\title{
Observation of Local Texture in Friction Stir Welding of Mg Alloy AZ31B to Steel
}

\author{
H. Yu ${ }^{1}$, Y. Hovanski ${ }^{2}$, D.P. Field ${ }^{1}$
}

${ }^{1}$ School of Mech. and Matls. Eng, Washington State University, Pullman, WA 99163-2920

${ }^{2}$ Pacific Northwest National Laboratories, 902 Battelle Blvd, Richland, WA 99354

Friction stir welding (FSW) is a solid state welding process that was developed in 1991 and has gathered considerable interest from both researchers and manufacturers [1]. Compared to traditional welding procedures, it is a pore-free and high efficiency technique. It is widely used in the joining of thin plate light metals and is gaining momentum for application to a plethora of other materials. Magnesium-based alloys are the lightest structural metals available for industry and attractive for their high damping capacity and specific stiffness, so they are often thought to be the material of choice for various applications, including automobile space frames. Joining of $\mathrm{Mg}$ alloys to steel and aluminum alloys are of primary importance for various applications. FSW of magnesium to steel for space frame applications will result in frames having high strength and high energy absorption capability. In this study, FSW of AZ31B to high strength low alloy steel (HSLA) and mild steel are taken into consideration separately. Electron backscatter diffraction (EBSD) was used to study the microstructures and determine the metal flow path for such welds.

The welding parameters for both systems are shown in Table 1. Samples were prepared for EBSD observation by typical grinding procedures using 240, 320, 400, 600, 1200 grit pads, with each succeeding step erasing all evidence of the former grinding step. Mechanical polishing was the main polishing method that produced good results. Due to the high corrosion susceptibility of AZ31B in water, alcohol based blue lube was used as the cooling solution in all polishing procedures. Three micron and $1 \mu \mathrm{m}$ diamond paste were used as the first two polishing steps using nylon cloths. 0.3 $\mu \mathrm{m}$ alumina suspension was then used on synthetic velvet cloth and the final step was colloidal silica suspension on MultiTex cloth. The pressure applied on the last two steps should not be on the order of 10 Newtons in order to get good patterns from EBSD. Polishing times of $30 \mathrm{~min}$ and $45 \mathrm{~min}$ were taken separately in the last two steps with rotation speeds of $500 \mathrm{rpm}$.

In the study of FSW of AZ31B to mild steel, an overall scan of the transverse section shows that the microstructures of AZ31B after welding can be divided into four different regions (shown as Figures 1 4); the interface is shown as Figure 5. More studies of each region show that each region can be divided to some other different regions according to the pole figures. Although the grain size of mild steel is big, the difference of the grain size in the interface is small (not shown in our figure). The microstructure of AZ31B near the interface shows a substantial difference in grain size between the weld nugget and the base metal, as well as unique structures near the region of metal contact with the weld tool shoulder. The difference may come from the large temperature gradients in that region. The study of AZ31B joined to HSLA shows a similar distribution, and as the grain size of HSLA is small compared with that of the mild steel, the grain size difference near the interface is small and nearly the same size of magnesium.

As the slip systems in magnesium alloys are limited, twinning often occurs during deformation, so the deformation mechanism is often a combination of slip and twinning. Suhuddin, et.al [2] argue that $\left\{\begin{array}{llll}1 & 0 & \overline{\mathbf{1}} & 2\end{array}\right\}$ twinning plus basal slip and prismatic slip domain the structure evolution. Beausir, 
et.al [3] define the different structure of magnesium according its Euler angles as fibers $B, P, Y, C_{1}$, and $C_{2}$ (Table 2). Our finding shows similar textures indicating that shear deformation dominates the process [4]

Reference

[1] Thomas WM. Friction stir butt welding. International Patent PCT/GB92/02203; 1991.

[2] U.F.H.R. Suhuddin, S. Mironov, Y.S. Sato, H. Kokawa, C.-W. Lee. Acta Materialia 57 (2009) 5406-5418

[3] Benoit Beausir, Satyam Suwas, Laszlo S. Toth a, Kenneth W. Neale, Jean-Jacques Fundenberger. Acta Materialia 56 (2008) 200-214

[4] The authors gratefully acknowledge the assistance of Dr. Scott Walck of South Bay Technologies and Dr. Carl Necker from Los Alamos National Laboratory for help in developing the sample preparation techniques.

Table1. Friction stir welding parameters

\begin{tabular}{ccccc}
\hline Rotation rate, $\mathrm{rpm}$ & Travel speed, $\mathrm{mm} / \mathrm{min}$ & Tilt & Plunge depth, $\mathrm{mm}$ & Weld length, mm \\
\hline 700 & 100 & $\mathbf{0}^{*}$ & 2.45 & 240 \\
\hline
\end{tabular}

Table2. Ideal orientations for hexagonal materials during ECAE [3]

\begin{tabular}{cccc}
\hline Fiber & $(\mathbf{q})$ & $\langle\mathbf{(})$ & $(\mathbf{p})$ \\
\hline $\mathrm{B}$ & 45 & 90 & $0-60$ \\
$\mathrm{P}$ & 45 & $0-90$ & 30 \\
$\mathrm{Y}$ & 45 & 30 & $0-60$ \\
$C_{1}$ & 105 & 90 & $0-60$ \\
$C_{2}$ & 165 & 90 & $0-60$ \\
\hline
\end{tabular}

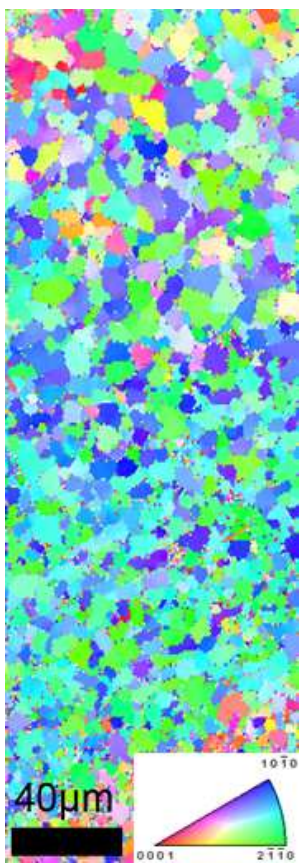

Fig.1 Region near TMAZ in AZ31B

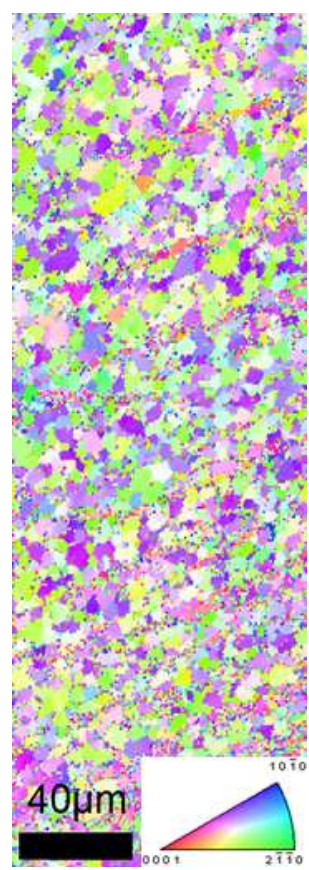

Fig.2 Region in nugget of AZ31B

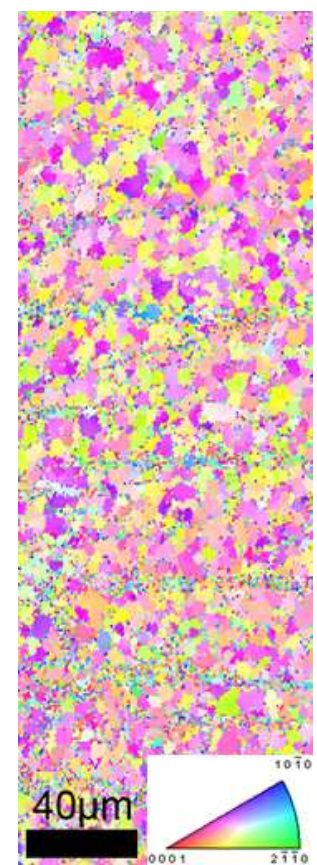

Fig.3 Region in nugget of AZ31B having a distinct structure

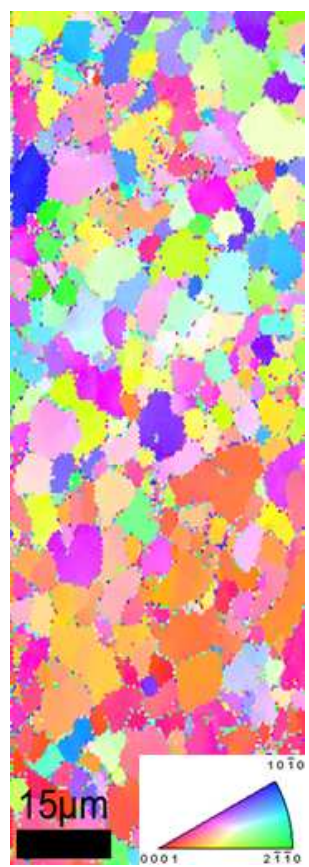

Fig.4 Region inAZ31B near the steel interface

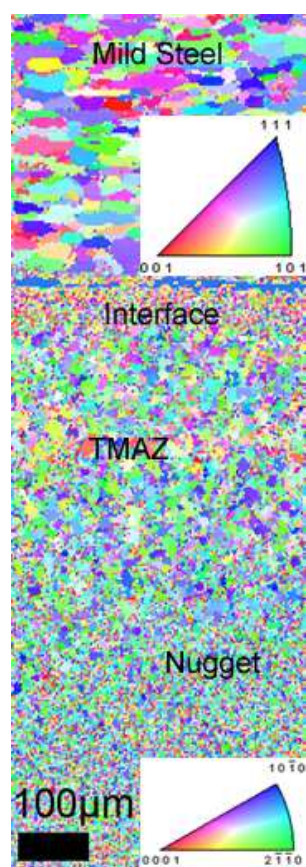

Fig.5 Mild steel-Mg interface region 